\title{
Comparison of Three Methods for the Purification of the Delta Haemolysin of Staphylococcus aureus
}

\author{
By GILLIAN M. SMITH AND WILLIAM V. SHAW* \\ Department of Biochemistry, University of Leicester, Leicester LE1 7RH
}

(Received 18 June 1980; revised 22 October 1980)

\begin{abstract}
Three methods for the purification of Staphylococcus aureus delta haemolysin were compared (Kantor et al., 1972; Kreger et al., 1971; Heatley, 1971). The products of these purifications from the culture supernatant of $S$. aureus strain RN25 were compared by electrophoresis, amino acid analysis, amino-terminal sequence analysis and thin-layer chromatography. The method of Heatley (1971) was found to be superior in terms of recovery and purity of the product. Delta haemolysin prepared by the method of Kreger et al. (1971) could not be sequenced successfully prior to treatment aimed at the removal of the $\mathrm{N}$-formyl group at the amino-terminus. Delta haemolysin appears to exist in two distinct molecular forms, one with $N$-formylmethionine and the other with un-formylated methionine in the amino-terminal position. The former polypeptide species is purified preferentially by the method of Kreger $e t$ al. (1971). Thin-layer chromatography of the products of each method of purification revealed that they were all heterogeneous, although the major component from the product of the method of Heatley (1971) represented not less than $70 \%$ of the product.
\end{abstract}

\section{INTRODUCTION}

Staphylococcus aureus produces a number of extracellular toxins (Bernheimer, 1974; Rogolsky, 1979). Delta haemolysin is one of several cytolytic toxins produced by the organism and is distinguished by some notable properties (McCartney \& Arbuthnott, 1978). It is relatively thermostable and can withstand heating to $80^{\circ} \mathrm{C}$ for $15 \mathrm{~min}$; it is hydrophobic in character and is soluble in a $2: 1(\mathrm{v} / \mathrm{v})$ mixture of chloroform and methanol; it has a high proportion of hydrophobic amino acids and is devoid of proline, arginine, tyrosine, cysteine and histidine. It also has a low specific haemolytic activity and exhibits little or no species specificity as regards the cell type used in the assay system. The toxin is inhibited by phospholipids, some fatty acids, normal serum and the alpha and beta globulin fractions of serum. It has been shown to be highly surface-active and its mode of action is thought to be detergent-like.

Delta haemolysin was first claimed to have been purified by Yoshida (1963) and subsequently by Kreger et al. (1971), Heatley (1971) and Kantor et al. (1972). Amino acid analyses of the products of these purification methods were similar and all showed a gross deficiency or absence of the residues noted above. There were, however, differences in the reported physico-chemical properties of the products, notably in ultracentrifugation studies, isoelectric focusing and polyacrylamide gel electrophoresis. The products of the purification methods of Kantor et al. (1972) and Kreger et al. (1971) have also been studied by Lee $e$ t al. (1976) and judged to contain varying but low levels of other toxic or enzymic activities.

The present study was designed to determine whether the reported differences between preparations of delta haemolysin are a consequence of the strains of $S$. aureus. used or arise from variations in isolation and purification techniques. The three most recently described 
methods were used to purify delta haemolysin from the culture supernatant of one genetically well defined strain and the products were compared directly by electrophoresis, amino acid analysis and partial or complete sequence determination. A preliminary account of these studies has been presented (Smith et al., 1979).

\section{METHODS}

Reagents. Unless otherwise stated reagents were obtained from Fisons Scientific Apparatus (Loughborough, Leics.) and were of analytical grade.

Bacterial strains. The study was performed with Staphylococcus aureus RN25 (kindly provided by Dr R. Novick). Strain RN25 is a derivative of strain RN1 which is lysogenic for at least three staphylococcal phages $(\phi 11, \phi 12$ and $\phi 13) ; \mathrm{RN} 25$ appears to harbour only phage $\phi 13$ (R. Novick, personal communication).

Maintenance of the organism. The strain was maintained on plates of Penassay base agar (Difco) kept at $4{ }^{\circ} \mathrm{C}$, and was subcultured monthly.

Growth of the organism. Staphylococcus aureus RN25 was grown in the yeast diffusate medium of Gladstone \& van Heyningen (1957). Small-scale cultures (10 $\mathrm{ml}$ volumes of sterile medium in $100 \mathrm{ml}$ Erlenmeyer flasks) were grown overnight at $37^{\circ} \mathrm{C}$ with shaking at $150-180 \mathrm{rev} \cdot \mathrm{min}^{-1}$ on a gyrotary shaker. Large-scale cultures $(500 \mathrm{ml}$ volumes of sterile medium in 21 Erlenmeyer flasks) were inoculated with $3 \mathrm{ml}$ of small overnight cultures and grown as described above. Cells were removed by centrifugation at $13000 \mathrm{~g}$ for $15 \mathrm{~min}$ at $20^{\circ} \mathrm{C}$. The supernatant was stored for up to a few days at $4{ }^{\circ} \mathrm{C}$ or for longer periods at $-20^{\circ} \mathrm{C}$.

Assay for haemolytic activity. Citrated human blood (type $\mathrm{O}, \mathrm{Rh}$ positive) from a single donor was washed five times in saline and finally resuspended in phosphate-buffered saline (PBS) pH 6.8 (Heatley, 1971). Blood was prepared fresh each week and stored at $4{ }^{\circ} \mathrm{C}$. Each week a standard curve was constructed using a stock solution of delta haemolysin purified from S. aureus strain $186 \mathrm{X}$ (supplied by Dr N. G. Heatley).

Samples for assay were made up to $0.5 \mathrm{ml}$ with PBS and mixed with $0.5 \mathrm{ml}$ of 25 -fold diluted erythrocyte suspension in PBS. The tubes were incubated for $15 \mathrm{~min}$ at $37^{\circ} \mathrm{C}$ with mixing and then centrifuged for $1.5 \mathrm{~min}$ at $12000 \mathrm{~g}$ at room temperature to remove unlysed cells and cell debris; $0.5 \mathrm{ml}$ samples of the supernatants were removed and added to $2.5 \mathrm{ml}$ portions of $0.1 \%(\mathrm{w} / \mathrm{v}) \mathrm{Na}_{2} \mathrm{CO}_{3}$ and mixed. A sample substituting water for PBS was taken to represent $100 \%$ haemolysis and the absorbance maximum of the resulting haemoglobin solution $(543 \mathrm{~nm})$ was used as the reference wavelength for the measurement of haemoglobin released in the haemolytic assay. For $100 \%$ haemolysis the absorbance at $543 \mathrm{~nm}$ was approximately 0.5 in all experiments. One haemolytic unit was taken as the amount of toxin yielding $50 \%$ haemolysis in the standard assay. Haemolytic activities of samples were calculated from a standard curve.

Estimation of protein. Protein was estimated by the Lowry method. Protein concentration was calculated from a standard curve constructed using Fraction V bovine serum albumin (Sigma).

Cell growth of strain RN25 and production of delta haemolysin. Sterile medium $(500 \mathrm{ml})$ in a 21 Erlenmeyer flask was inoculated with $5 \mathrm{ml}$ of a small overnight culture $\left(A_{540} 16 \cdot 8\right)$. At $30 \mathrm{~min}$ intervals $1 \mathrm{ml}$ samples were removed. Part of each sample $(0.5 \mathrm{ml})$ was heat-treated at $60^{\circ} \mathrm{C}$ for $1 \mathrm{~h}$ to remove any alpha haemolysin; any precipitate that appeared was removed by centrifugation at $12000 \mathrm{~g}$ at room temperature for $3 \mathrm{~min}$. The supernatant was assayed for delta haemolysin. The remainder of each sample was used to monitor growth turbidimetrically at $540 \mathrm{~nm}$. Reliable measurement of changes in the total protein in the culture fluid was not possible because of the rich growth medium used.

Purification of delta haemolysin. Delta haemolysin was purified from the culture supernatant of $S$. aureus strain RN25 by three different methods.

1. Selective desorption from alumina $C \gamma$ gel (Kantor et al., 1972). This method involved adsorption of delta haemolysin to aluminium hydroxide gel (alumina $\mathrm{C} \gamma$ gel; Sigma). The method of Kantor et al. (1972) was adhered to closely. In our case, however, a higher gel to protein ratio of 1.5 was required to achieve $90 \%$ adsorption of the haemolytic activity when the culture supernatant was mixed with the gel. The gel was washed with $0.08 \mathrm{M}$-phosphate buffer $\mathrm{pH} 7.2$ and then eluted with $0.5 \mathrm{M}$-phosphate buffer $\mathrm{pH} \mathrm{7.2.} \mathrm{When} \mathrm{the} \mathrm{eluted} \mathrm{protein} \mathrm{was}$ dialysed against distilled water a precipitate appeared; this was not reported by the original authors. The precipitate was removed by centrifuging for $10 \mathrm{~min}$ at $6000 \mathrm{~g}$ at $4{ }^{\circ} \mathrm{C}$, lyophilized and assayed for haemolytic activity. The supernatant was concentrated as described in the original report and then lyophilized.

2. Chromatography on hydroxylapatite (Kreger et al., 1971). This method involved adsorption of delta haemolysin to hydroxylapatite gel (Biogel HTP; Bio-Rad Laboratories). The gel was mixed with the culture supernatant and then washed first with $0.01 \mathrm{M}$-phosphate buffer $\mathrm{pH} 6.8$ and then with $0.4 \mathrm{M}$-phosphate buffer $\mathrm{pH} 6.8$. The haemolytic activity was eluted with $1.0 \mathrm{M}$-phosphate buffer $\mathrm{pH} 7.4$. The precipitate which appeared on dialysis of the eluate against distilled water was removed by centrifuging for $10 \mathrm{~min}$ at $6000 \mathrm{~g}$ at $4{ }^{\circ} \mathrm{C}$, 
lyophilized and assayed for haemolytic activity. The supernatant was concentrated as described in the original report and then lyophilized.

3. Solvent transfer method (Heatley, 1971). The parameters of this method were investigated by Heatley $(1971 ; 1976)$. It involves precipitation of the haemolysin by the addition of chloroform (final concentration $1.5 \%$, $\mathrm{v} / \mathrm{v}$ ) to an acidified heat-treated culture supernatant. The toxin is then extracted from the precipitate with chloroform/methanol $(2: 1$, by vol.) and purified by transfer between the two phases of chloroform/ methanol/water $(10: 5: 3$, by vol.). The haemolysin distributes mainly in the lower phase under neutral conditions and in the upper phase under acid conditions (Heatley, 1971).

Supernatant fluid was heated to $60^{\circ} \mathrm{C}$ and maintained at this temperature with occasional stirring for $1 \mathrm{~h}$. The resulting precipitate was removed by centrifuging at $16000 \mathrm{~g}$ for $45 \mathrm{~min}$ at $20{ }^{\circ} \mathrm{C}$. The supernatant was removed and adjusted to $\mathrm{pH} 5.3$ with $5 \mathrm{M}$-phosphoric acid, chloroform was added (final concentration $1.5 \%$, v/v) and the mixture was stirred overnight at room temperature. The dark grey precipitate which appeared was collected by centrifuging at $16000 \mathrm{~g}$ for $45 \mathrm{~min}$ at $4^{\circ} \mathrm{C}$ and washed by resuspension in $120 \mathrm{ml}$ of $0.01 \mathrm{M}$-phosphate buffer $\mathrm{pH} 6.8$ saturated with chloroform. The suspension was again centrifuged at $4^{\circ} \mathrm{C}$ and the resulting precipitate was resuspended in $270 \mathrm{ml}$ of chloroform/methanol $\left(2: 1\right.$, by vol.) and left overnight at $4^{\circ} \mathrm{C}$. The precipitate was again collected by centrifugation and the clear, yellowish supernatant fluid was filtered through Whatman no. 1 paper. To this supernatant was added $50 \mathrm{ml}$ of $0.1 \mathrm{M}$-phosphate buffer $\mathrm{pH} 6.8$ with thorough mixing. The phases were left to separate for about $1 \mathrm{~h}$ at room temperature. The lower layer (expected to contain the toxin) was removed and the upper layer was again extracted with $170 \mathrm{ml}$ of chloroform $/ \mathrm{methanol} /$ water ( $86: 14: 1$, by vol.). The lower layer was again removed and pooled with that of the first extraction. The pooled lower layers were then extracted five times with $20 \mathrm{ml}$ of acidified chloroform/methanol/water $(3: 48: 47$, by vol.), containing sequentially $100,300,200,200$ and $200 \mu \mathrm{l}$ of $1 \mathrm{M}$-phosphoric acid. Each of the five extracts was then treated with $125 \mathrm{ml}$ acetone to precipitate the protein. A white precipitate appeared in the first and second extracts. The precipitates were centrifuged as before, the supernatants were removed and the precipitates were dried under vacuum overnight.

Polyacrylamide gel electrophoresis. Electrophoresis was performed in gel slabs $(15 \times 14 \times 0.2 \mathrm{~cm})$ in a vertical apparatus at room temperature at constant voltage. Stacking was carried out at $60 \mathrm{~V}$ and separation was achieved at $120 \mathrm{~V}$ for approximately $3 \mathrm{~h}$.

Electrophoresis in the presence of sodium dodecyl sulphate (SDS). The method used was based on that of Laemmli et al. (1970) using a ratio of acrylamide to bisacrylamide of $77: 1$ for $10 \%(\mathrm{w} / \mathrm{v})$ acrylamide gels, $173: 1$ for $15 \%(\mathrm{w} / \mathrm{v})$ acrylamide gels and $239: 1$ for $17.5 \%(\mathrm{w} / \mathrm{v})$ acrylamide gels. Electrophoresis was towards the anode using bromophenol blue $(0 \cdot 1 \%, w / v)$ as the tracking dye.

Gradient gel electrophoresis in the presence of SDS. This was carried out using gels with a linear gradient $(10-30 \%, w / v)$ of acrylamide under the conditions outlined above.

Electrophoresis under non-denaturing conditions (alkaline $\mathrm{pH}$ ). The system outlined for SDS electrophoresis was used omitting SDS from all buffers. The sample buffer was replaced by $50 \mathrm{mM}$-Tris/HCl buffer $\mathrm{pH} 7.8$ containing $0.1 \mathrm{M}-2$-mercaptoethanol plus glycerol ( 1 drop in each sample). The gels were electrophoresed as above.

Electrophoresis under non-denaturing conditions (acidic $p H$ ). 'Native' electrophoresis was also carried out in the acidic system of Reisfeld et al. (1962). Electrophoresis was towards the cathode using methyl green $(0.5 \%, w / v)$ as the tracking dye.

Staining and destaining. Gels were stained overnight at room temperature in a solution containing $2 \mathrm{~g}$ PAGE blue G-90 and $100 \mathrm{~g}$ trichloroacetic acid in 1 litre of $40 \%(\mathrm{v} / \mathrm{v})$ methanol in distilled water. Gels were destained at room temperature in $7 \%(\mathrm{v} / \mathrm{v})$ acetic acid.

Amino acid analysis. Amino acid analyses were performed using a single column amino acid analyser by the method of Spackman et al. (1958). Samples were hydrolysed in $6 \mathrm{M}-\mathrm{HCl}$ containing $10 \mu \mathrm{M}$-phenol for 24,48 and $72 \mathrm{~h}$ at $105^{\circ} \mathrm{C}$ in sealed, evacuated tubes. Chromatograms of the samples and standards were integrated automatically and data were normalized by the method of Ambler (1975).

$N$-terminal amino acid sequence analysis. Automated amino-terminal sequencing of the products of the three purification procedures was performed using an Anachem APS 2400 solid-phase sequencer based on the principles described by Laursen (1971). The samples were coupled to isothiocyanate-glass (Machleidt et al., 1973). Phenyl thiohydantoin amino acids were identified by silica gel thin-layer chromatography (Bridgen et al., 1975).

Thin-layer chromatography. Thin-layer chromatography of the products of the three purification procedures was used as an alternative to polyacrylamide gel electrophoresis for assessing their purity. Thin-layer plates $(20 \times$ $20 \mathrm{~cm} ; 0.25 \mathrm{~mm}$ silica gel; Polygram Sil G, Camlab, Cambridge) were used. Samples $(0.5 \mathrm{mg})$ of each delta haemolysin preparation were dissolved in water and spotted across the origin. The chromatogram was developed in $n$-butanol/water/acetic acid $(45: 30: 25$, by vol.) for about $4 \mathrm{~h}$, air dried and then stained by spraying with cadmium ninhydrin reagent (Glazer et al., 1975). The ninhydrin-positive areas were circled and the chromatogram was then re-stained for tryptophan-containing peptides using Ehrlich's reagent (Glazer et al., 1975). 


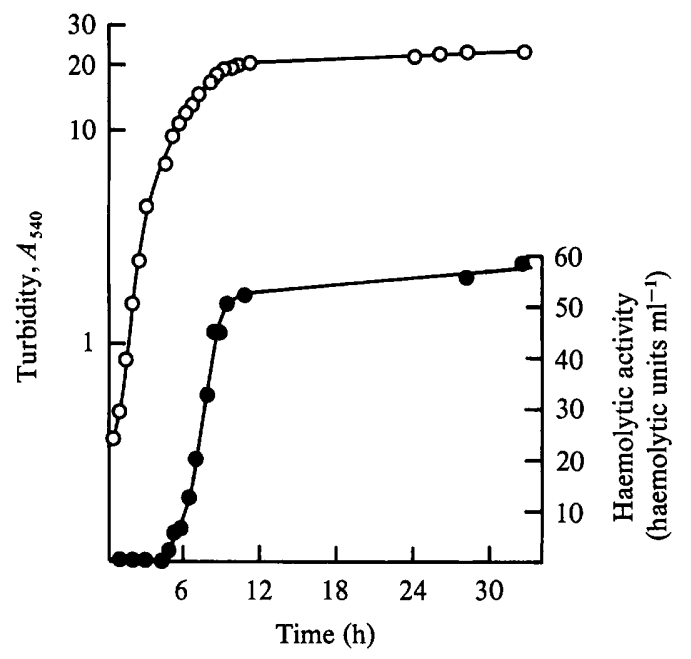

Fig. 1. Growth of $S$. aureus strain RN25 and production of delta haemolysin. Samples of the culture fluid were taken at the times indicated for measurement of turbidity $(\mathrm{O})$, and for assay of haemolysin (O) after removal of bacteria by centrifugation. Growth was at $37^{\circ} \mathrm{C}$ in the medium described in Methods.

Table 1. Purification of delta haemolysin by three different methods

\begin{tabular}{lccc}
\multicolumn{1}{c}{ Method } & $\begin{array}{c}\text { Recovery } \\
(\%)\end{array}$ & $\begin{array}{c}\text { Specific activity } \\
\text { of final product } \\
\text { (haemolytic units } \mathrm{mg}^{-1} \text { ) }\end{array}$ & $\begin{array}{c}\text { Purification } \\
\text { factor }\end{array}$ \\
Kantor et al. $(1972)$ & 12.3 & 52 & 4.7 \\
Kreger et al. $(1971)$ & 29.0 & 67 & 5.6 \\
Heatley (1971) & 46.0 & 149 & 13.4
\end{tabular}

\section{RESULTS}

\section{Growth of S. aureus RN25 and production of delta haemolysin}

Delta haemolysin was produced in the late-exponential phase of growth and reached a constant level in the stationary phase (Fig. 1). All cultures were therefore grown overnight and harvested approximately $15-17 \mathrm{~h}$ after inoculation.

\section{Purification of delta haemolysin}

1. Selective desorption from alumina $C \gamma$ gel (Kantor et al., 1972). The results of the purification are shown in Table 1 . Recovery was low. Only $60 \%$ of the toxin adsorbed to the gel was eluted and losses were considerable during the long dialysis and concentration steps. The purification factor and the specific activity of the product were the lowest of the three purification methods tested. The appearance of a precipitate on dialysis was comparable with that seen in the method of Kreger et al. (1971). The precipitate represented $5 \%$ of the initial activity but only accounted for $20 \%$ of the loss of activity on dialysis. The specific activity of the precipitate was slightly higher than that of the product.

2. Chromatography on hydroxylapatite (Kreger et al., 1971). The results of the purification are shown in Table 1. The appearance of a precipitate in the dialysis step was reported previously by Kreger et al. (1971) and was described as 'insoluble' delta haemolysin. They reported that it represented $35 \%$ of the total activity purified. The precipitate which appeared in the dialysis step in the present study represented $21 \%$ of the total activity purified 


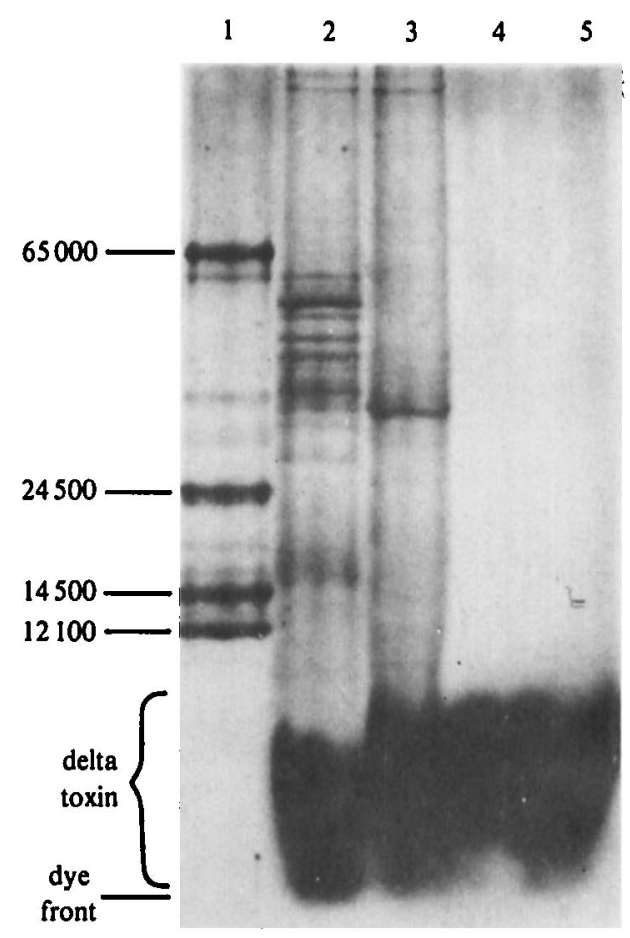

Fig. $2(a)$

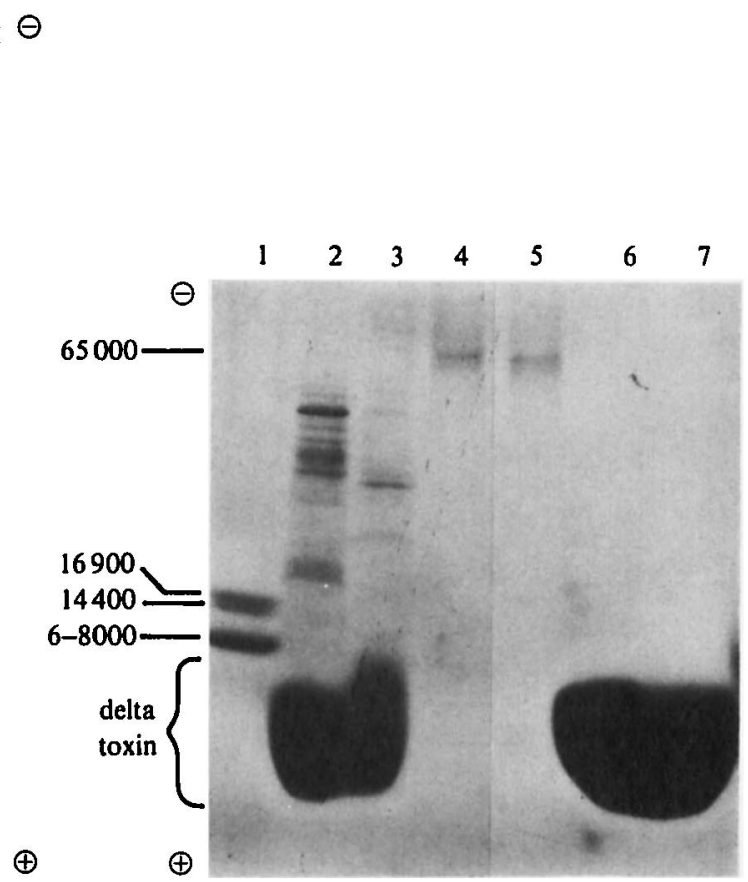

Fig. $2(b)$

Fig. 2. Polyacrylamide gel electrophoresis in the presence of SDS.

(a) In $15 \%(\mathrm{w} / \mathrm{v})$ acrylamide: track 1 , standards - Fraction $\mathrm{V}$ bovine serum albumin (mol. wt $65000)$, chymotrypsinogen (24500), lysozyme (14500) and RNAase (12100); 2, $250 \mu \mathrm{g}$ delta haemolysin purified by the method of Kantor et al. (1972); 3, $250 \mu \mathrm{g}$ delta haemolysin purified by the method of Kreger et al. (1971); 4, $250 \mu \mathrm{g}$ delta haemolysin purified by the method of Heatley (1971); 5, $250 \mu \mathrm{g}$ delta haemolysin supplied by $\mathrm{Dr}$ N. G. Heatley, purified by his method from $S$. aureus $186 \mathrm{X}$.

(b) In a linear gradient of 10-30\% (w/v) acrylamide: track 1, myoglobin standards - mol. wt 16900 , 14400 and $6000-8000 ; 2,250 \mu \mathrm{g}$ delta haemolysin purified by the method of Kantor et al. (1972); 3, $250 \mu \mathrm{g}$ delta haemolysin purified by the method of Kreger et al. (1971); 4 and 5, Fraction V bovine serum albumin (mol. wt 65000); 6, $250 \mu \mathrm{g}$ delta haemolysin purified by the method of Heatley (1971); 7, $250 \mu \mathrm{g}$ delta haemolysin supplied by Dr N. G. Heatley, purified by his method from S. aureus $186 \mathrm{X}$.

and had 1.3 times the specific activity of the 'soluble' delta haemolysin product. Recovery was better than that obtained by the method of Kantor et al. (1972) (see above), the greatest loss of activity occurring in the dialysis and concentration steps. The precipitate of 'insoluble' delta haemolysin only represented $16 \%$ of the loss of activity on dialysis. The degree of purification and specific activity of the product were also higher than achieved by the method of Kantor $e t$ al. (1972).

3. Solvent transfer method (Heatley, 1971). As indicated in Table 1, this method resulted in the highest recovery and the highest specific activity of delta haemolysin of the three methods used. The method was found to be simple, reproducible and very much quicker than the other two methods.

\section{Polyacrylamide gel electrophoresis}

The products of the three purification methods were compared with a sample purified by the method of Heatley (1971) from $S$. aureus 186 X and kindly donated by him.

It was necessary to overload the gels in order to visualize the delta haemolysin. In SDS gels (Fig. $2 a$ ) the delta haemolysin ran as a very diffuse band just behind the dye front with an apparent molecular weight of less than 10000 . The products of purification by the methods of 


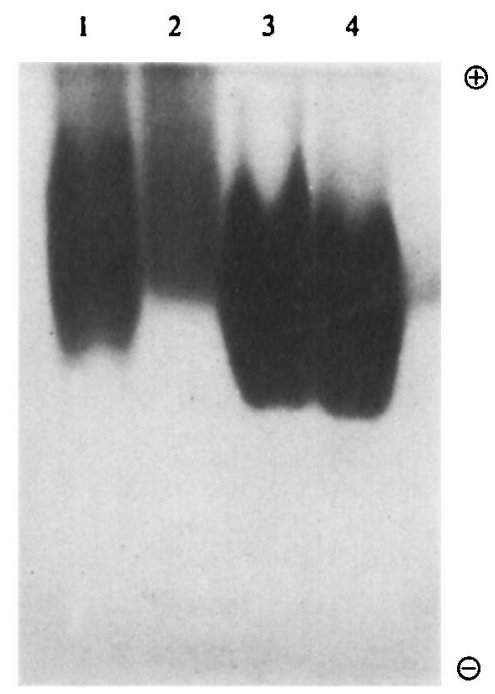

Fig 3. Electrophoresis under non-denaturing conditions in the acidic system of Reisfeld et al. (1962). Electrophoresis was performed in $15 \%(\mathrm{w} / \mathrm{v})$ acrylamide gels. Track $1,250 \mu \mathrm{g}$ delta haemolysin purified by the method of Kantor et al. (1972); 2, $250 \mu \mathrm{g}$ delta haemolysin purified by the method of Kreger et al. (1971); 3, $250 \mu \mathrm{g}$ delta haemolysin purified by the method of Heatley (1971); 4, $250 \mu \mathrm{g}$ delta haemolysin supplied by Dr N. G. Heatley, purified by his method from $S$. aureus $186 \mathrm{X}$.

Kantor et al. (1972) and Kreger et al. (1971) showed multiple additional bands with higher apparent molecular weights. These could in principle be either impurities or aggregates of delta haemolysin. Delta haemolysin prepared by all three methods did not stain well in spite of heavy loading and care in destaining. This phenomenon is thought to be an inherent property of the molecule which may have led previously to emphasis being given to the additional bands in the preparations obtained by the methods of Kantor et al. (1972) and Kreger et al. (1971).

Polyacrylamide gradient gels in the presence of SDS (Fig. $2 b$ ) were run in an attempt to sharpen the delta haemolysin band and estimate more accurately the molecular weight of the toxin polypeptide. The delta haemolysin still ran as a diffuse band with an apparent molecular weight of less than 7000 . Additional bands such as were noted previously were again observed in the delta haemolysin purified by the alumina or hydroxylapatite methods. Insulin B chain and melittin, which have molecular weights very similar to that calculated for delta haemolysin from amino acid sequence analysis (Fitton et al., 1980), also ran as diffuse bands under the same conditions (results not shown). This observation suggests that, with the conditions employed for electrophoresis under denaturing conditions, the diffuseness of the delta haemolysin band is a simple consequence of molecular size.

In alkaline systems without SDS the preparations of delta haemolysin did not enter the gel but remained at the origin, whereas in the acidic system of Reisfeld et al. (1962) they ran as a diffuse band (Fig. 3). The preparations obtained by the methods of Kantor et al. (1972) and Kreger et al. (1971) had slightly lower mobilities. Two sets of samples were run in this experiment, one set on each half of the gel. Half of the gel was visualized by staining for protein whereas each track in the other half of the gel was cut into $5 \mathrm{~mm}$ strips which were pulverized in $0.2 \mathrm{ml} \mathrm{PBS}$ and eluted overnight at $37^{\circ} \mathrm{C}$ prior to assay for haemolytic activity. Haemolytic activity in each track was localized only to that part of the track which corresponded to the diffuse band visualized by the protein stain.

\section{Amino acid analysis}

The amino acid analyses of the products of the three purification procedures were similar in that they all lacked proline, arginine, histidine and tyrosine, although there were slight 
Table 2. Amino acid analyses of delta haemolysin purified by three different methods

\begin{tabular}{|c|c|c|c|c|c|}
\hline \multirow[b]{2}{*}{$\begin{array}{c}\text { Amino } \\
\text { acid }\end{array}$} & \multirow[b]{2}{*}{$\begin{array}{l}\text { Expected no. } \\
\text { of residues } \\
\text { from sequence }\end{array}$} & \multicolumn{4}{|c|}{ Purification method and strain } \\
\hline & & $\begin{array}{l}\text { Kantor et al. } \\
(1972) \\
\text { from RN25 }\end{array}$ & $\begin{array}{l}\text { Kreger et al. } \\
\quad(1971) \\
\text { from RN25 }\end{array}$ & $\begin{array}{c}\text { Heatley } \\
(1971) \\
\text { from RN25 }\end{array}$ & $\begin{array}{c}\text { Heatley } \\
(1971) \\
\text { from 186X }\end{array}$ \\
\hline Asx & 4 & $2 \cdot 8$ & $3 \cdot 0$ & $3 \cdot 3$ & $3 \cdot 0$ \\
\hline Thr & 3 & $2 \cdot 0$ & $2 \cdot 1$ & $2 \cdot 4$ & $2 \cdot 7$ \\
\hline Ser & 1 & $1 \cdot 1$ & $1 \cdot 5$ & $1 \cdot 0$ & 0.9 \\
\hline Glx & 1 & 1.4 & $1 \cdot 5$ & $1 \cdot 3$ & $1 \cdot 2$ \\
\hline Pro & 0 & 0.0 & 0.0 & 0.0 & 0.0 \\
\hline Gly & 1 & $1 \cdot 8$ & 1.8 & $1 \cdot 7$ & $1 \cdot 8$ \\
\hline Ala & 1 & $2 \cdot 3$ & $1 \cdot 7$ & 1.4 & 1.4 \\
\hline Cys & 0 & - & - & - & - \\
\hline Val & 2 & $2 \cdot 8$ & $3 \cdot 1$ & 1.6 & $1 \cdot 0$ \\
\hline Met & 1 & 1.5 & $1 \cdot 0$ & $1 \cdot 1$ & 1.0 \\
\hline Ile & 5 & $3 \cdot 3$ & 4.7 & $5 \cdot 1$ & 4.7 \\
\hline Leu & 1 & $2 \cdot 1$ & 1.8 & 1.4 & 1.4 \\
\hline Tyr & 0 & 0.0 & 0.0 & 0.0 & 0.0 \\
\hline Phe & 1 & 0.9 & $1 \cdot 1$ & 1.4 & 1.7 \\
\hline $\mathrm{His}$ & 0 & 0.0 & 0.0 & 0.0 & 0.0 \\
\hline $\operatorname{Trp}$ & 1 & - & - & - & - \\
\hline Lys & 4 & $4 \cdot 0$ & $2 \cdot 8$ & $4 \cdot 2$ & $4 \cdot 3$ \\
\hline Arg & 0 & 0.0 & 0.0 & 0.0 & 0.0 \\
\hline Total & 26 & & & & \\
\hline
\end{tabular}

differences in the amounts of the other amino acids (Table 2). The amino acid analysis of the product obtained by the purification method of Heatley (1971) agreed very well with that of the delta haemolysin provided by Dr N. G. Heatley and purified from $S$. aureus strain $186 \mathrm{X}$ by his method.

\section{$N$-terminal amino acid sequence analysis}

Analysis of the delta haemolysin prepared by the methods of Kantor et al. (1972) and Heatley (1971) gave the following amino-terminal sequence: $\mathrm{NH}_{2}-\mathrm{X}-\mathrm{Ala}-\mathrm{Gln}-\mathrm{Asp}-$ Ile-Ile-Ser-Thr-Ile-Gly-Asp-Leu-Val-X-Trp-Ile-Ile-Asp-Thr-Val-Asn-X-Phe-Thr$\mathrm{X}-\mathrm{X}$, where $\mathrm{X}$ signifies that no phenyl thiohydantoin amino acid was detected. Lysine residues and the amino-terminal residue are not usually seen due to the method of attachment of the polypeptides to the glass support. This sequence, together with the amino acid analyses of the products, suggested that their amino acid sequences were identical with that found by Fitton et al. (1980) for delta haemolysin purified by Dr N. G. Heatley by his method from $S$. aureus $186 \mathrm{X}$, containing $N$-terminal methionine. Repeated attempts to determine the $N$-terminal sequence of delta haemolysin purified by the method of Kreger et al. (1971) were unsuccessful, suggesting that the terminal amino acid was blocked. Mass spectrometry of delta haemolysin purified by the method of Heatley (1971) from $S$, aureus 186 X showed that a proportion of it contained $N$-formylmethionine (Fitton et al., 1980). When the Kreger preparation was treated with $1 \mathrm{M}-\mathrm{HCl}$ in methanol for $1 \mathrm{~h}$ at room temperature to unblock the amino-terminus (Fitton et al., 1980), subsequent sequence analysis revealed that the first ten residues were the same as in the other preparations.

\section{Thin-layer chromatography}

An example of the separation achieved using thin-layer chromatography is shown in Fig. 4. Delta haemolysin purified in this study by the method of Heatley (1971) was identical chromatographically with that supplied by Dr N. G. Heatley; however, each preparation was found to be heterogeneous. The most densely stained spot is believed to be delta haemolysin. The preparations of delta haemolysin purified by the methods of Kantor et al. (1972) and 


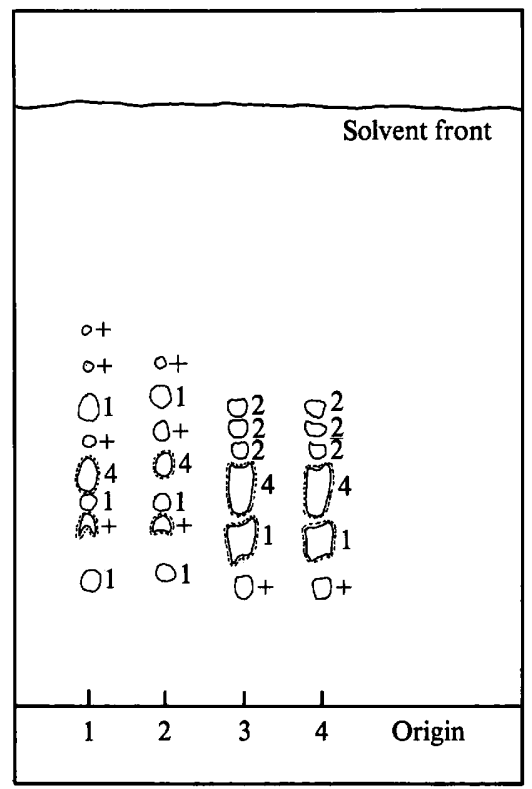

Fig. 4. Thin-layer chromatography of the products of the three delta haemolysin purification procedures. The continuous outlines represent areas stained with ninhydrin and the dashed outlines represent tryptophan-positive areas stained with Ehrlich's reagent. The intensities of the stained areas are indicated according to the scale: + , faint; 1 to 4 , in order of increasing intensity. The solvent system was $n$-butanol/water/acetic acid $(45: 30: 25$, by vol.). Track 1 , delta haemolysin purified by the method of Kantor et al. (1972); 2, delta haemolysin purified by the method of Kreger et al. (1971); 3, delta haemolysin purified by the method of Heatley (1971); 4, delta haemolysin supplied by Dr N. G. Heatley, purified by his method from $S$. aureus $186 \mathrm{X}$.

Kreger et al. (1971) differed in that they exhibited additional spots; however, they also yielded densely staining spots attributable to delta haemolysin. In each case this spot was also the most tryptophan-positive spot when stained to detect tryptophan. When this spot was eluted and assayed for haemolytic activity it was found to be active whereas controls from other regions of each track were negative (data not shown).

\section{DISCUSSION}

Comparison of the products of the three different purification procedures for delta haemolysin revealed several slight differences between them. Each method gave a different recovery and a different degree of purification. The method of Kantor et al. (1972) gave a very low recovery and purification, with the greatest loss of activity occurring during dialysis and concentration. The method of Kreger et al. (1971) gave recoveries and purification which were only modestly better than those obtained by the method of Kantor et al. (1972). Both methods were mechanically clumsy, labour intensive and time-consuming: large volumes of eluate had to be dialysed and concentrated. Both resulted in the appearance of a white precipitate on dialysis of the eluate which represented $20-40 \%$ of the purified haemolytic activity. This was first observed by Kreger et al. (1971) and referred to as 'insoluble' delta haemolysin. The method of Heatley (1971) was technically the simplest and quickest and resulted in the highest recovery and overall purification.

Polyacrylamide gel electrophoresis in the presence of SDS revealed differences between the three preparations in that those obtained by the methods of Kantor et al. (1972) and Kreger et al. (1971) exhibited multiple additional high molecular weight bands; these could be due to impurities or, less likely, aggregates of the toxin. Delta haemolysin appeared as a major and 
very diffuse band of apparent molecular weight of less than 7000 in all of the preparations. In the acidic system of Reisfeld et al. (1962) without SDS the preparations all ran as diffuse bands with almost identical mobilities. Haemolytic activity was localized over the whole of the diffuse bands. This heterogeneity of the preparations might account for some of the discrepancies which have arisen in connection with previously published studies of delta haemolysin. Differences appear, therefore, to be due to methods of preparation as the strain used in this study was the same for each method. This is supported by the fact that delta haemolysin prepared by the method of Heatley (1971) from different strains appeared to be identical.

Slight differences in the amino acid analyses were observed for the three different preparations of delta haemolysin. However, none contained proline, arginine, tyrosine and histidine. This suggests that the additional stained bands observed after polyacrylamide gel electrophoresis in SDS were either aggregates of the monomeric delta haemolysin or contaminating proteins which were quantitatively unimportant. We favour the latter view since the higher molecular weight species did not give a regular pattern nor did they appear with the preparation purified by the solvent transfer method. The difficulty encountered in staining delta haemolysin by conventional methods suggests that other workers may have drawn attention to bands on SDS gels which were contaminants rather than the delta haemolysin which was certainly present. These contaminants appeared to be more readily excluded from the final preparation by the organic solvent transfer method than by the other techniques which rely on aqueous solvents.

The $N$-terminal sequence of the preparations purified by alumina adsorption or the solvent transfer method agreed with that found for delta haemolysin prepared by the method of Heatley (1971) from $S$. aureus 186X (Fitton et al., 1980). Mass spectrometry of the latter preparation of delta haemolysin showed that in addition to the unblocked peptide, $\mathrm{N}$-formylmethionine was present at the amino-terminus of a proportion of these molecules. Treatment of the product prepared by the method of Kreger et al. (1971) with methanolic $\mathrm{HCl}$ yielded a polypeptide which was identical with other preparations for the first ten amino acid residues of the primary structure. It seems likely, therefore, that delta haemolysin exists in culture filtrates in at least two forms, the unblocked polypeptide and the $N$-formyl blocked form, and that the latter is preferentially purified by the method of Kreger et al. (1971).

Thin-layer chromatography revealed that all the preparations consisted of several components of which the delta haemolysin was the most prominent and which represented visually not less than $60 \%$ of the total peptide applied. Sequencing data firmly in agreement with the sequence found by Fitton et al. (1980) also suggest that the delta haemolysin is the major component. However, it is believed that perhaps a family of similar molecules are purified by the methods employed including the two forms of delta haemolysin.

We conclude that the principal component of the $S$. aureus delta haemolysin purified from the same culture supernatant by three different methods is a 26 residue polypeptide which is identical in primary structure to that described recently by Fitton et al. (1980). The single and probably important qualification is that each of the three methods yields a product which contains a variable amount of the $N$-formylated terminal methionyl delta haemolysin. The hydroxylapatite chromatography procedure yields this molecule exclusively, whereas the alumina $\mathrm{C} \gamma$ gel method and the solvent transfer procedure yield mixtures of both molecular species, the formyl-blocked product being the major component in the latter. Studies are in progress to determine whether the $N$-formyl delta haemolysin is the amino-terminal sequence of a unique membrane-associated or secreted protein which is synthesized in large amounts or whether it serves as a leader or signal sequence for a family of such proteins.

We thank Dr N. G. Heatley for his advice and encouragement and for reference samples of delta haemolysin purified by his method. The Science Research Council and The Wellcome Foundation provided support in the form of a C.A.S.E. studentship to Gillian Smith. We are grateful to Dr J. E. Fitton and J. Keyte for assistance with $N$-terminal sequence and amino acid analyses. 


\section{REFEREN CES}

Ambler, R. P. (1975). The amino acid sequence of Staphylococcus aureus penicillinase. Biochemical Journal 151, 197-218.

BERNHEIMER, A. W. (1974). Interactions between membranes and cytolytic bacterial toxins. Biochimica et biophysica acta 344, 27-50.

Bridgen, J., Graffeo, A., KARger, B. L. \& WATERFIELD, M. (1975). The identification of PTH amino acids. In Instrumentation in Amino Acid Sequence Analysis, pp. 111-145. Edited by R. N. Perham. London: Academic Press.

Fitton, J. E., Dell, A. \& Shaw, W. V. (1980). The amino acid sequence of the delta haemolysin of Staphylococcus aureus. FEBS Letters 115, 209212.

Gladstone, G, P. \& van Heyningen, W. E. (1957). Staphylococcal leucocidins. British Journal of Experimental Pathology 38, 123-137.

Glazer, A. N., Delange, R. J. \& Sigman, D. S. (1975). Detection reagents for peptides and amino acids. In Chemical Modification of Proteins, p. 183. Edited by T. S. Work \& E. Work. Amsterdam: North-Holland Publishing Co.

Heatley, N. G. (1971). A new method for the preparation and some properties of staphylococcal delta-haemolysin. Journal of General Microbiology 69, 269-278.

Heatley, N. G. (1976). Unusual behaviour of a protein: reversible quantitative precipitation of staphylococcal delta haemolysin by low concentrations of some organic solvents. International Journal of Peptide and Protein Research 8, 233-236.

Kantor, H. S., Temples, B. \& Shaw, W. V. (1972). Staphylococcal delta haemolysin: purification and characterisation. Archives of Biochemistry and Biophysics 151, 142-146.

KREGER, A. S., KWANG-SHIN KIM, ZABORETSKY, F. \& Bernheimer, A. W. (1971). Purification and pro- perties of staphylococcal delta haemolysin. Infection and Immunity 3, 449-465.

LAEMMLI, U. K. (1970). Cleavage of structural proteins during the assembly of the head of bacteriophage T4. Nature, London 227, 680-685.

LAursen, R. A. (1971). Solid-phase Edman degradation. An automatic peptide sequencer. European Journal of Biochemistry 20, 89-102.

LeE, S.-H., Sarauskas, T., Hoy, E. S. \& Riaz-ul HAQUE (1976). Purity of staphylococcal delta haemolysin obtained by three different procedures. Journal of Medical Microbiology 9, 371-377.

MACHLEIDT, W., Wachter, E., Scheulen, M. \& OTTO, J. (1973). Solid-phase Edman degradation of a protein: $N$-terminal sequence of cytochrome $c$ from Candida krusei. FEBS Letters 37, 217-220.

MCCartney, A. C. \& ARbuthnotT, J. P. (1978). Mode of action of membrane-damaging toxins produced by staphylococci. In Bacterial Toxins and Cell Membranes, pp. 89-127. Edited by J. Jeljaszewicz \& T. Wadström. London: Academic Press.

Reisfeld, R. A., Lewis, U. J. \& Williams, D. E. (1962). Disk electrophoresis of basic proteins on polyacrylamide gels. Nature, London 195, 281-283.

Rogolsky, M. (1979). Nonenteric toxins of Staphylococcus aureus. Microbiological Reviews 43, 320 360.

Smith, G. M., Fitron, J. E. \& Shaw, W. V: (1979). Delta haemolysin of Staphylococcus aureus: purification, structure and biosynthesis. Society for General Microbiology Quarterly 6, 147.

Spackman, D. H., Stein, W. H. \& Moore, S. (1958). Automatic recording apparatus for use in the chromatography of amino acids. Analytical Chemistry 30, 1190-1206.

YoshidA, A. (1963). Staphylococcal $\delta$-haemolysin. 1. Purification and chemical properties. Biochimica et biophysica acta 71, 544-553. 